\title{
The Role of Academic Development Practitioners towards Institutionalizing the Scholarship of Teaching and Learning: A Case Study
}

\author{
Dr Noluthando Toni
}

\section{Ms. Cindy-Leigh Martinson}

\author{
University of Fort Hare \\ Teaching and Learning Centre, East London \\ ntoni@ufh.ac.za and cmartinson@ufh.ac.za
}

\section{Doi:10.5901/mjss.2014.v5n11p11}

\begin{abstract}
In this paper the authors who are Academic Developers discuss their efforts on the institutionalization of the Scholarship of Teaching and Learning (SoTL) at a South African Higher Education Institution. The 2013 annual colloquium referred to as the Teaching and Learning week is used as one example of many platforms for the dissemination of scholarly teaching and learning. Academic Developers at this institution use this form of dissemination as a means to institutionalize SoTL. Focusing on this specific platform as a single case study provides an opportunity to emphasise the importance of the SoTL in the strengthening university teacher's pedagogical approaches to teaching and learning. This paper is based on the efforts of promoting academics engagement in SoTL and the explication of academic developers' roles in the institutionalization of SoTL. A critical analysis of the 2013 Teaching and Learning Week provides insight into the importance of the enhancement of academics approaches to teaching and the facilitation of learning. The paper attempts to debunk the incorrect perception of viewing teaching as a common sense activity. Scholarly teaching is explored as an intellectual activity intended to bring about documented developments in student learning, and those developments are shared publicly. The Teaching and Learning Week creates a physical and intellectual space for discussions on scholarly teaching to take place. From this point SoTL is producing knowledge which is available for public critique and use. In turn this legitimizes the actions and work of the presenting university teachers. As professional educators, they have an obligation to participate in pedagogical research and the sharing thereof.
\end{abstract}

Keywords: Scholarship of Teaching and Learning, Academic Development, Higher Education, Public Platforms, Student Learning, Institutionalization.

\section{Introduction and Background}

The Scholarship of Teaching and Learning (SoTL) has according to Paino, Blankenship, Grauerholz and Chin (2012) occupied a position of accumulating significance in academia since the publication of the Scholarship Reconsidered by Ernest Boyer in 1990. SoTL has been noted as a social movement by a number of authors amongst others Blumer (1969), Smelser (1962) and Tilly (1978). Social movements take place within social institutions where the goal is to improve current systems within that social institution rather than replace the current systems. McKinney (2012) highlights the SoTL as a movement within higher education which has founded renewed interest in teaching and learning and has requested an increase in academic professionals accountability to teaching and learning. Alongside any social movement come frustrations with the status quo, injustices and untapped knowledge. The members of the SoTL community share common beliefs and attitudes about teaching and learning and the importance thereof. McKinney (2012) establishes that we are beyond the developing stage of these social movements and are functioning at the collaborative stage.

The members who have aligned themselves with this social movement have been named as Academic Developers (AD) who concern themselves with the strengthening and improving the student learning, teaching and assessment practices. AD members are there for working towards constantly challenging the status quo within the realm of teaching and learning and also seek to empower academics in their quest for innovative and transformational ways of teaching and learning. This enables academics to question their practice in studying their discipline in a way which reveals the best practice for teaching within their discipline. Henning (2004, p. 23) credits critical theory for invoking a critical approach in the lived experiences and social relations of communities. Critical theory in this paper is premised from moving away from questioning the discipline, but rather questioning the pedagogies of how the discipline is taught. In realising that having been taught in a specific way does not mean that one should teach in the same way, one should rather look for new and 
innovative approaches to teach in a way which produces scholarly teaching and learning. Lecturers (also referred to in the paper as academics) who have invested in AD make use of AD platforms to share their personal experiences and relationships formed with their students which help to shape their teaching experiences. Using the underpinnings of critical theory, this paper seeks to show how lecturers can empower both themselves and their students through the scholarship of their teaching. "As critical theory aspires to confront the injustices of a particular community, it is also concerned with how people tackle issues ... in an attempt to construct a social system" (Toni, 2009, p. 28). AD Centres concern themselves with the teaching and learning associated with lecturers and students across their respective disciplines. Due to this focused interest in the improvement of teaching and learning a perspective has surfaced that all teaching and learning problems are housed within higher education institution's AD Centres. AD Centres, therefore, seek to encourage individual freedoms within teaching and learning in a drive towards shared knowledge and improved scholarship.

Modern institutions of higher education have four main areas of function: research, teaching, service, administration and management (Arimoto, 2014). The focus placed on these areas by academics of Higher Education institutions depend on the evaluation and reward system for each core function. Modern higher education institutions are highly rewarded for research, which is formally publicized and as such much individual focus is placed on producing publications. Teaching unfortunately is being considered as a common sense activity (Hutchings, Huber \& Ciccone, 2011). Scholarly teaching is an intellectual activity intended to bring about documented developments in student learning and share them publicly (Carlson-Dakes, 2005). Scholarly teaching is an intellectual activity intended to bring about documented developments in student learning, and those developments should be shared publicly. This sharing has a potential to institutionalize the culture of scholarly teaching.

Earnest Boyer (1990) speaks of teaching being rendered public and open to critical evaluation and thus useable by others. Shulman (1998) suggest that the scholarship of teaching entails a public account of some or all of the following aspects of teaching-vision, design, interaction, outcomes, and analysis-in a manner that can be peer reviewed and used by members of one's community. Therefore, publication need not be formal, but can also be informal and take the form of any type of public sharing. This, however, does not carry with it the prestige of formal publication. Boyer (1990) suggests that higher education move beyond the outdated separation of teaching and research. It is of importance that we do not merely focus on the aspect of teaching but on researching what has been rendered public and improve upon it. This requires that academics carefully plan and examine their forms of teaching in an academically sound and investigative manner which ensures the professionalization of teaching which ultimately improves students' access to learning. Howery (2002) warned that if SoTL is conducted only or predominantly by faculty at teaching-oriented institutions, it risks being seen as "interest-group scholarship," and its respectability will suffer. Cottrell and Jones (2003, pp. 169-170) identify Shulman's five elements of SoTL (mentioned above) as "a framework from which to analyse current efforts to maximize students' learning and each is a necessary part of the scholarship of teaching and learning". This paper, therefore, argues for concerted efforts to institutionalise SoTL for the enhancement of teaching and learning.

Academic Developers should teach and work towards transforming institutional cultures grounded in evidence about our students' learning, and that scholarly teaching is critical to our work (Huber \& Hutchings, 2005). "Students in higher education in South Africa as elsewhere in the world are wanting teachers, with the formative pedagogical practices they bring and not lecturers as purely 'information downloaders"' (McMillan, 2007, p. 213). McMillan (2007) raises the issue that it is not enough for university teachers to be experts in their discipline, but that they should also seek to be experts in the teaching of their discipline to ensure scholarly learning is taking place. One way of doing this is by infusing and applying research processes through the scholarship of teaching and learning (SoTL). Drawing from, among others, Pecorino and Kincaid (2007), McKinney et al, (2007) and Ciccone's (2011) views on creating spaces for communicating as an institutional platform to discuss pedagogical practices and process, the paper specifically focuses on current contributions of $A D$ Centres in ensuring that teaching and learning continue to be practiced in a scholarly manner. The paper draws from activities of the AD Centre of a South African university to demonstrate how the implementation of SoTL is institutionalised.

\section{Advancing the SoTL through the Academic Development Unit}

$A D$ activities at one South African university are coordinated within the institution's Teaching and Learning Centre (TLC). Among its various roles, the TLC is also responsible for promoting the engagement of academics in the SoTL. The TLC, as the centre that is concerned with promoting scholarly teaching and learning, has the privilege of constantly interacting and engaging with both academics and students. The centre is aware of the challenges experienced by both academics and students in the process of mediating learning. AD practitioners also have the privilege of witnessing the excellent 
work that takes place in the classrooms. It was for this reason that a large and a safe platform was created to share and/or disseminate good practice. Annual symposia referred to as Teaching and Learning Weeks, were initiated. These symposia are meant for sharing excellent work done by both students and lecturers, showcasing good practice, exploring new ways of addressing challenges in the classroom, and ultimately learning from one another. This is a notion that is practiced by scholars of teaching and learning when new spaces are created for pedagogical exchanges and collaborations (Hutchings, Huber and Ciccone, 2011). This is in an attempt to move academics away from the school of thought that links scholarship only to research, but rather to introduce scholarship as a connection between teaching and research in a symbiotic relationship. Glassick, Huber and Maeroff (1997) suggest that for the scholarship of teaching to take place several elements must be clear including presentation and reflective critique. As stated earlier, the AD unit (TLC) provides these two elements through the symposia of the Teaching and Learning (TL) Week.

\title{
3. University Teachers' Understanding of SoTL as Perceived by AD Practitioners
}

Lecturers often, but not in all cases, see themselves as experts in their chosen pedagogy and thus do extensive research and community work in one particular pedagogy (Pecorino and Kincaid, 2007). However, the truth of the matter is that lecturers are not only experts in their fields but also professional teachers in higher education. With this role comes the responsibility to do research into that area to improve not only your own practice, but to offer information to the wider community in which one exists. Pecorino and Kincaid (2007) speak of lecturers being aware of SoTL but seeing it as improving their own teaching practices and as a 'slice' of research which does not interest them within their departments. "And as professional educators, they have an obligation to participate in pedagogical research" (Pecorino and Kincaid, 2007, 3). Bayles (1981) defines a profession as having the following conditions a) extensive training, b) a significant intellectual component and c) provision of important service to society. Bayles also states that the common features of a profession are a) certification and/or licensing, both external and internal, b) organization of members and c) professional autonomy. The United Nations Educational, Scientific and Cultural Organization (United Nation Educational, Scientific and Cultural Organization [UNESCO], 1997, sec. 3, para. 6) confirms:

\begin{abstract}
"Teaching in higher education is a profession: it is a form of public service that requires of higher education personnel expert knowledge and specialized skills acquired and maintained through rigorous and lifelong study and research; it also calls for a sense of personal and institutional responsibility for the education and welfare of students and of the community at large and for a commitment to high professional standards in scholarship and research."
\end{abstract}

As university teachers employed as professionals by a higher education institution they have an ethical responsibility to not only be experts in their discipline, but to be active researchers within their discipline in such a way as to become experts in how to teach their discipline effectively, to ensure scholarly learning takes place.

Hutchings et al. (2011) state that what lecturers bring to the SoTL table are issues which matter most to them. They collect their information through descriptive questions, confirmatory questions, visions of the possible and questions related to themes and typologies (Hutchings, 2000). Most importantly, they present material which is answerable. The 2013 symposium, involved showcasing disciplinary ways of knowing, presenting teaching, learning and assessment challenges and possible solutions, as well as exploring new innovations in teaching and learning. We will further elaborate on this when giving an abridged account of the symposium. Shulman (1998, cited by Vardi and Quin, 2011) describes this as a 'public' account of one's teaching. Pecorino and Kincaid (2007) refer to an obligation of disseminating results of formal and informal pedagogic research by all professional post-secondary school educators. This dissemination, they claim, can be conducted informally and formally. Overall, the TLC provides a platform through, TL Week, which creates a physical and intellectual space for the SoTL to take place. From this point SoTL is producing knowledge which is available to public critique and use. In turn, this legitimizes the actions and work of the presenting lecturer. The entire presentation of course must be influenced by research surrounding the lecturer's enquiry so as to ensure a scholarly approach.

\section{Methodology}

This is a case study within a single higher education institution within South Africa in which we investigate the why and how of scholarly teaching being institutionalized. This case study is undertaken in an attempt to obtain rich and in-depth data. Yin (1984) defines the case study method as an empirical inquiry that investigates a current phenomenon within its everyday context; when the limitations between phenomenon and context are not visibly apparent; and in which various 
sources of substantiation are used. The institutionalization of scholarly teaching is an everyday occurrence which takes place in a multitude of contexts which overlap and have no definite boundaries. Practitioners analysing this event draw on a number of sources as evidence when analysing and reflecting on the event. The AD practitioners critically analysed the Teaching and Learning Week event by looking at the reports generated after the event, through observations during the event and feedback received from participants of the event. The limitations of this approach concern the lack of generalizability and the potential for researcher bias. The researchers, therefore, acknowledge their interest and role within this study and are aware of the event's importance for them as Academic Developers and yet maintain a critical approach to ensure that promotion of critical consciousness and awareness precedes analysis (Henning, 2004).

\section{Lesson from the 2013 Teaching and Learning Week}

In explicating the importance of the SoTL in their context, Makura and Toni (2014) put emphasis on the idea of academics as university teachers having a moral obligation to pass on epistemologies derived from teaching praxis to the wider community of practice. This is an idea that is widely published, by and among others (Kreber, 2002; Paino, Blankenship, Grauerlolz and Chin, 2012; and Vardi and Quin, 2011), that scholarship must be disseminated and be critiqued by peers.

As mentioned earlier, one of the reasons behind the introduction of TL Weeks is to showcase good practice, explore new ways of addressing challenges in the classroom. Kreber (2002) postulates that the scholarship of teaching is not solely meant to produce publications. She asserts that scholars of teaching and learning constantly explore various ways of making their work public. TL weeks serve the purpose of providing a platform for academics to make their work public through formal presentations and deliberations around those presentations. In the succeeding section we share lessons learnt and what transpired during the 2013 symposium which revolved under the theme "An integrated approach: Towards Scholarly Excellence". The emphasis was on promoting the scholarship in the three pillars of the university, to further elaborate: teaching and learning, research and community engagement. Teaching and learning enjoyed prominence.

\subsection{Creating Space for communicating and disseminating pedagogical experiences and research within the institution}

Drawing from, among others, Pecorino and Kincaid (2007), McKinney et al, (2007) and Hutchings et al. (2011) views on creating spaces for communicating about teaching and learning, the TLC utilises the TL week to serve that purpose. The 2013 TL week served as a viable institutional platform to discuss pedagogical practices and process. The symposium also served as a platform to further explore the value of theorising about teaching and learning. The TL weeks are not necessarily the only platforms available at the university. There are other platforms available at departmental and discipline levels. The research unit of the university also provides similar platforms. We are specifically focusing on the TL week because the rationale of the paper is about highlighting the role played by the TLC as an AD unit in the institutionalization of SoTL. The Centre can be described as an institution-wide entity that provides support to both academics and students through a variety of initiatives, programmes and services in teaching development, academic staff, the development of student learning, and the integration of technology enhanced learning. The TL weeks manage to re-enforce $A D$ efforts at the institution as well as make the Centre accessible to all staff and students regardless of their disciplines.

\subsection{Dissemination of scholarship}

Kreber (2002) is of the view that the scholarship of teaching is described in various ways. She however leans towards viewing it as a continuum where it is equated to teaching excellence as well as publications in peer-reviewed media. She further cites Shulman (1998) where emphasis is put on giving a public account in a manner that can be peer-reviewed and utilized by members of one's community. It is for this reason that we perceive our annual symposia as a viable dissemination platform. We need to also hasten to mention that this does not provide the complete continuum. Publishing in peer reviewed publications is considered as the next step of disseminating to a wider and international audience. Most importantly, our aim is to improve practice for better efficiency.

During the 2013 symposium academics showcased their action research projects on student learning and the impact of various assessment strategies on students' performance. Strategies shared included demonstrations on the visualisation techniques employed in the instruction of mathematics. Among strategies shared in maximising participation in lessons were applying the jig-saw model in various and relevant sections of the curricula, using places and spaces to 
create an active learning environment; various ways of instilling the reading culture through making students read for leisure, and relating content to real life examples where students could enjoy the process of learning and gain epistemological access. Various approaches were shared on how potentially 'at risk' students are supported. Practical ideas were shared around incorporating technology to minimise the stress of assessment in large classes. Most presentations by academics illustrated areas where scholarly teaching is practised. A few of the presentations were either closer to or at the end of the SoTL loop, in other words, placing the ideas shared through the symposium presentations in the public domain as published articles.

The section above is intentionally kept broad in the sense that no in-depth explication is given about the intricacies of papers. This is to demonstrate the possibilities of transferring certain approaches and/or teaching and learning strategies from one discipline to the next. Participants were further given an opportunity of refining their presentations into publishable articles in publications of their choice and disciplines. The presenters were given access to a mentor who would act as a critical reader to assist them in the writing process. It is expected that the finished articles will be submitted in journals of various disciplines, hence the details of the presentations are kept to the minimum in this paper. What was of utmost importance during the symposium were demonstrations of the learning journeys of students and lecturers discovering new ways of teaching and assessing.

\section{Conclusions, Reflective and Summative Ideas Emanating from the Symposium}

\subsection{Identification and promotion of scholarly and innovative teaching at all levels}

There is a need to establish strengthened, structured, and systematic ways of identifying and harnessing innovative and scholarly teaching taking place within and across disciplines at departmental levels (micro levels). These innovative practices would then be elevated to broader and macro levels such as the TL weeks and national conferences and symposia. Such publicity and sharing at various levels will ensure that "codes of good practices" and innovations taking place at micro levels are showcased for university-wide learning.

Teaching and learning innovations taking place at micro levels are a fertile ground for SoTL. SoTL research needs to be built into the planned innovations and not come as an after-thought. Implementation thereof must be thought through carefully and deviations and lessons be recorded for further development.

\subsection{Teaching and Research interconnectedness}

An important observation was highlighted on the last day of the four day symposium. Among the presenters were three esteemed researchers who were awarded the university's Research Excellence Awards. This serves as a demonstration of the strong link between research and teaching. An assertion was made of leading researchers taking their teaching seriously and making efforts to improve, innovate, and further develop teaching and learning. Furthermore, a need for critical examination of institutional professional development efforts was identified as a viable strategy to strengthen the scholarship of teaching and learning within the institution. This is informed by the prominence of Teaching and Learning Excellence Award recipients and those who have been through the formal professional qualification for university teachers.

\subsection{Possible Scholarly Teaching and Learning Investigations}

The guest and international presenter (USA), Dr Anthony Ciccone highlighted the importance of reflective inquiry around how students learn (process) and why they learn (the value of learning). The approach points to thinking about teaching and learning as challenging and intellectual work. University teachers therefore should move from the instructional paradigm to a learning paradigm. Investigations into students' learning experiences can assist lecturers in enhancing their teaching approaches and improve student learning.

\subsection{Recognising and Rewarding Teaching Excellence at micro levels}

Recognising and rewarding teaching excellence within disciplines, academic departments and faculties can provide opportunities to incorporate SoTL in the work of departments and faculties. This is taken further by influencing institutional procedures in recognising and awarding excellent teachers. Previously, this recognition was done at the institutional level where only two academics were awarded. From the year 2014, Teaching Excellence Awards will be given for the first 
time in the history of the institution at faculty levels as well as at institutional level. This change will expose more lecturers to opportunities of being recognised. Furthermore, the status of teaching will receive more prominence and "excellent teachers" will receive validation.

\title{
7. Recommendations
}

This paper serves as a demonstration that in order for university communities to fully appreciate that teaching is a scholarly act, there need to be conscious efforts to engage in activities that portray university teaching as such. Based on the reflective and summative ideas that emanated from the analysis of the 2013 TL week, the following recommendations are suggested:

\begin{abstract}
University teachers should constantly reflect on how they teach, how students respond to various approaches to teaching and learning, as well as determine new ways of facilitating the learning for both themselves (teachers) and their students. Student feedback, therefore, is a key factor in enriching the information gathered by teachers about learning experiences of their students. Various instruments and strategies must be used in soliciting student feedback.
\end{abstract}

Numerous platforms for disseminating codes of good practice should be created and be widely publicised. Creating and promoting a culture of sharing pedagogical approaches will ultimately improve student learning and also enrich the scholarship of teaching and learning. Roxå, Olsson and Mårtenson (2008, p. 278) speak of "Teaching and Learning Regimes" which encompass socially constructed traditions and habits encompassed in and around how learning and teaching are facilitated in a particular discipline. New members coming into the discipline would not only be inducted into the ethos of the discipline, but would also be part of critical examinations and investigations conducted to promote critical inquiry into the teaching and learning of the discipline.

Academic Development Centres or Units should play an active role in creating platforms within and across disciplines for academics to engage in deliberate discussions about pedagogical aspects of their disciplines. These units should not solely be perceived as resource centres for staff and student support and development, but should also serve as academic hubs for pedagogical aspects of the academy. AD units should constantly seek, establish, and provide physical and intellectual spaces for the exploration and sharing of transformative and alternative pedagogical approaches.

\section{References}

Arimoto, A. (2014). Balancing the Scholarship of Teaching and Research, and Faculty Evaluation Systems. In Shin, J, C., \& Teichler, U. (Eds.), The Future of the Post-Massified University at the Crossroads (pp. 167-182). doi: 10.1007/978-3-319-01523-1

Bayles, D. (1981). Professional Ethics. Belmont: Wadsworth Incorporated.

Blumer, H. (1969). Collective Behavior. In A. M. Lee (Ed.), Principles of sociology (pp. 165 - 221). New York, NY: Barnes and Noble.

Boyer, E. (1990). Scholarship Reconsidered. San Francisco: Jossey-Bass.

Carlson-Dakes, C. (2005). Creating a Collaborative Environment a guidebook. Madison: Center for the Integration of Research, Teaching, and Learning (CIRTL).

Cottrell, S., Scott, A., \& Jones, E. (2003). Researching the Scholarship of Teaching and Learning: An Analysis of Current Curriculum Practices. Innovative Higher Education, 27(3), 169-181.

Glassick, C. E., Huber, M. T., \& Maeroff, G. I. (1997). Scholarship assessed: Evaluation of the professoriate. San Francisco: JosseyBass.

Henning, E. (2004). Finding your way in qualitative research. Pretoria: Van Schaik.

Howery, C. B. (2002). The Culture of Teaching in Sociology. In Huber, M. T., \& Morreale, S. P. (Eds.), Disciplinary Styles in the Scholarship of Teaching and Learning: Exploring Common Ground (pp. 143-62), Washington: American Association for Higher Education.

Huber, M. T., \& Hutchings, P. (2005). Surveying the Scholarship of Teaching and Learning. In Huber, M. T., \& Hutchings, P. (Eds.), The Advancement of Learning: Building the Teaching Commons (pp. 1-16). Retrieved from http://www.carnegiefoundation.org/sites /default/files/publications/elibrary_pdf_635.pdf

Hutchings, P. (2000). Opening Lines: Approaches to the Scholarship of Teaching and Learning. Pittsburgh: Carnegie Foundation for the Advancement of Teaching.

Hutchings, P., Huber, M. T., \& Ciccone, A. (2011). The Scholarship of Teaching and Learning Reconsidered. San Francisco: JosseyBass.

Jeffrey, C., Senter, M., \& Spalter-Roth, R. (2011). Love to Teach, but Hate Assessment? Teaching Sociology, 39(2), 120-26.

Kreber, C. (2002). Teaching Excellence, Teaching Expertise, and the Scholarship of Teaching. Innovative Higher Education, 27(1), 5-23.

Makura, A.H., \& Toni, N. (2014). Managing the link between Academic Development and the Scholarship of Teaching and Learning: The 
Case of South African Universities. International Journal of Educational Sciences, 6(1), 85-93.

McKinney, K. (2007). Enhancing Learning through the Scholarship of Teaching and Learning: The Challenges and Joys of Juggling. San Francisco: Jossey-Bass.

McKinney, K. (2012). Making a difference: Application of SoTL to enhance learning. Journal of the Scholarship of Teaching and Learning, 12(1), 1-7.

McMillan, W. (2007). "Then you get a teacher" Guidelines for excellence in teaching. Medical Teacher, 29(8), 209-218.

Paino, M., Blankenship, C., Grauerholz, L. , \& Chin, J.(2012). The Scholarship of Learning and Teaching Sociology. Teaching Sociology, 40(2), 93-106.

Pecorino, P., \& Kincaid, S. (2007). Why Should I Care About SOTL? The Professional Responsibilities of Post-Secondary Educators. International Journal for the Scholarship of Teaching and Learning, 7(2), 1-6.

Roxå, T., Olsson, T. \& Mårtenson, K. (2008). Appropriate Use of Theory in the Scholarship of Teaching and Learning as a Strategy for institutional Development. Arts and Humanities in Higher Education. 7(3), 276-294.

Shulman, L. S. (1998). Course anatomy: The dissection and analysis of knowledge through teaching. In Hutchings, P. (Eds.), The Course Portfolio: How faculty can examine their teaching to advance practice and improve student learning (pp. 5-13). Washington: American Association for Higher Education.

Smelser, N. J. (1962). Theory of Collective Behavior. New York: Free Press

Tilly, C. (2004). Social Movements, 1786-2004. Boulder: Paradigm Publishers.

Toni, N. 2009. Breaking down subtle and implicit racial divides in Higher Education Institutions: An Educational Management perspective. (Doctoral Thesis). Nelson Mandela Metropolitan University. Port Elizabeth.

United Nation Educational, Scientific and Cultural Organization [UNESCO]. (1997). Recommendation concerning the Status of HigherEducation Teaching Personnel. Retrieved from: http://portal.unesco.org/en/ev.php-url_id=13144\&url_do=do_topic\&url_section $=201$. html

Vardi, I. \& Quin, R. (2011). Promotion and the Scholarship of Teaching and Learning. Higher Education Research and Development, 30(1), $39-49$.

Yin, R. K. (1984). Case study research: Design and methods. Newbury Park, CA: Sage. 
